\title{
Sentra Batik Sebagai Destinasi Wisata Dengan Pendekatan Kearifan LOKAL Di SURAKARTA
}

\author{
Reza Septian Dwiputra, Made Suastika, Amin Sumadyo. \\ Program Studi Arsitektur \\ Universitas Sebelas Maret Surakarta \\ Email : trixities06@gmail.com
}

\begin{abstract}
In this modern era, batik fashion has begun to be ignored by the entry of foreign fashion culture that makes clothing in the country is less desirable. With declining public interest in Indonesian culture of batik, the authors took the initiative wants facilitate batik entrepreneurs large and small, to cooperate in preserving and developing batik. Not only provide container, but gave the tourist attractions in batik. So, traveled as well as learn about batik. Containers to be built covers several activities related to batik. Batik is not only in terms of clothing, batik can be applied to the world of architecture such as the application forms of the motif into the building. Implementation into the building that is the basic form, the skin and the elements in buildings. The issue is how to design a form Sentra Batik design by applying the concept of Local Wisdom, which raises the shape of the building with a mix of local culture and foreign culture. The method used is the method of architectural design. The result of the design of a regional architecture concept Sentra Batik with Local Wisdom is applied to the shape of the building as Joglo with a combination of forms of batik motif on building elements.
\end{abstract}

Keywords: Batik, Batik Tourism, Local Wisdom, Sentra Batik.

\section{PENDAHULUAN}

Perkembangan batik di Indonesia mulai sejak masa Kerajaan Mataram Islam, yang bersumber dari keraton, seperti motif parang rusak, semen rama dan lain-lain. Batik dikenal sebagai desain dalam busana. Saat ini batik sudah kurang diminati karena perkembangan zaman. Generasi muda saat ini pun kurang akan keingintahuan akan batik seperti sejarah batik maupun pembelajaran membatik.

Berkaitan dengan hal ini, sangat diperlukan upaya khusus untuk menggugah minat generasi muda Indonesia untuk melestarikan dan mengembangkan batik untuk di masa yang akan datang sebagai budaya Indonesia dengan belajar membatik dan melanjutkan usaha dan industri batik yang sudah berjalan.

Dalam mengembangkan batik di Indonesia diperlukan wadah untuk menginsipirasi masyarakat luas dan mengembangkan akan budaya batik. Tidak hanya dalam busana, tetapi budaya batik dapat diaplikasikan ke dalam bentuk maupun elemen yang digunakan pada bangunan, untuk memperlihatkan budaya batik yang begitu mempesona ke dunia. Dalam hal mengembangkan batik, dimulai dari asal muasal batik di Indonesia, yaitu Kota Surakarta dan Yogyakarta. Di Yogyakarta sudah mulai dikembangkan budaya batik dengan mempromosikan wisata batik dengan tempattempat batik di Yogyakarta kepada masyarakat luas, tidak hanya masyarakat Indonesia saja, akan tetapi ke masyarakat seluruh dunia.

Sentra Batik mewadahi para pengusaha kecil maupun besar batik untuk melakukan pameran maupun untuk dijual bentuk desain batik miliknya dengan bersama-sama di Galeri Sentra Batik.

Sentra Batik memiliki fungsi ganda dengan beberapa kegiatan yang dijadikan satu di satu kawasan Sentra Batik. Fungsi ganda menghubungkan kegiatan utama maupun pendukung.

\section{METODE}

Dalam proses perancangan proyek ini ada beberapa hal mengenai elemen-elemen arsitektur yang diterapkan dari konsep Kearifan Lokal pada tiap aspek perancangan.

Konsep Kearifan Lokal (Local Wisdom) yang diambil dari Ayat, (1986) dalam aspek arsitektur yaitu :

1. Mampu bertahan terhadap budaya luar. 
2. Memiliki kemampuan mengakomodasi unsur-unsur budaya luar.

3. Mempunyai kemampuan mengintegrasikan unsur budaya luar ke dalam budaya asli.

4. Mempunyai kemampuan mengendalikan.

5. Mampu memberi arah pada perkembangan budaya.

Kearifan Lokal (Local Wisdom) yang digunakan yaitu Kearifan Lokal rumah Jawa. Dari lay out peruangan rumah Jawa, bentuk bangunan dan elemen bangunan. Penerapan Kearifan Lokal ke dalam rancangan Sentra Batik, yaitu dengan bentuk atap Joglo dan limasan ke beberapa bangunan, bentuk motif batik ke dinding maupun secondary skin pada beberapa bangunan.

\section{ANALISIS}

\subsection{Analisis Peruangan}

Peruangan dalam Sentra Batik dibagi atas beberapa massa, yaitu sebagai berikut:

Tabel 1.Kebutuhan Ruang

\begin{tabular}{|l|l|}
\hline \multicolumn{1}{|c|}{ Kegiatan } & Kebutuhan Ruang \\
\hline Area Parkir & Parkir pengunjung \\
\cline { 2 - 2 } Bagian Museum dan & Parkir pengelola \\
\cline { 2 - 2 } & Ruang penerima \\
\cline { 2 - 2 } & Museum batik \\
\cline { 2 - 2 } & Gudang batik \\
\cline { 2 - 2 } & Ruang kebersihan \\
\cline { 2 - 2 } & Ruang membatik \\
\hline Bagian Galeri & Galeri batik \\
\cline { 2 - 2 } & Ruang ganti/kamar pas \\
\cline { 2 - 2 } & Gudang batik \\
\hline \multirow{5}{*}{ Bagian Penginapan } & Ruang penerima dan \\
pembayaran
\end{tabular}

\subsection{Analisis Pengolahan Tapak}

\subsubsection{Analisis Lokasi dan Pencapaian}

Lokasi Sentra Batik ada di perbatasan antar Kota Surakarta dengan Kota Karanganyar yang dapat dilihat pada Gambar 1.

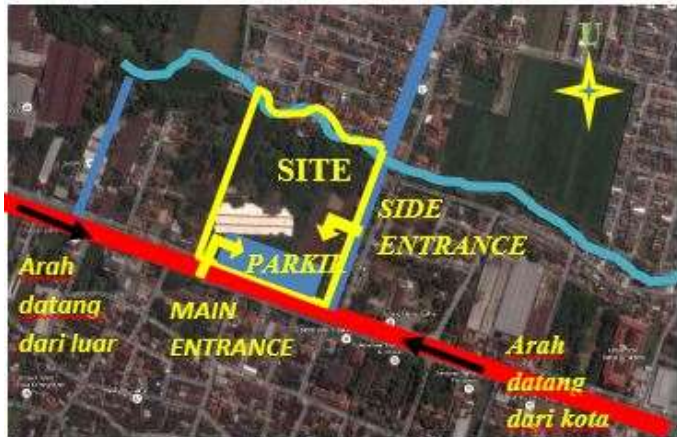

Gambar 1. Lokasi Terpilih sumber: google earth

Berlokasi di pinggir jalan utama, pencapaian ke Sentra Batik mudah dan akses di dalam kawasan Sentra Batik mudah dicapai dengan sirkulasi kendaraan yang teratur dan aman bagi semua pengguna. Dengan menggunakan dua akses masuk yaitu main entrance dan side entrance untuk menghindari adanya penumpukan kendaraan dalam kawasan.

\subsubsection{Analisis Pemintakan (Penzoningan)}

Dengan berlokasi di Kota Surakarta yang kental dengan budaya Jawa maka pemintakatan dilakukan sesuai dengan lay out peruangan rumah Jawa yang dapat dilihat pada Gambar 2 .

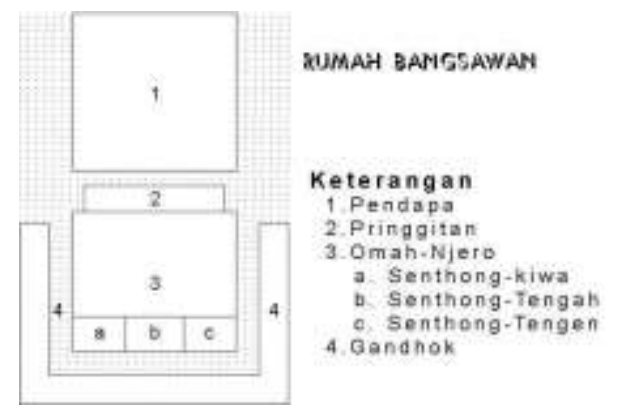

Gambar 2. Pola Peruangan Rumah Jawa Tipe Bangsawan

sumber: http//www.hdesignideas.com/2011/01/tataruang-rumah-adat-jawa-tengah

Analisis Pemintakatan (Penzoningan) disesuaikan dengan lay out peruangan rumah Jawa. Kawasan Sentra Batik memilik 6 masa bangunan yang dapat dilihat pada Gambar 3 . 


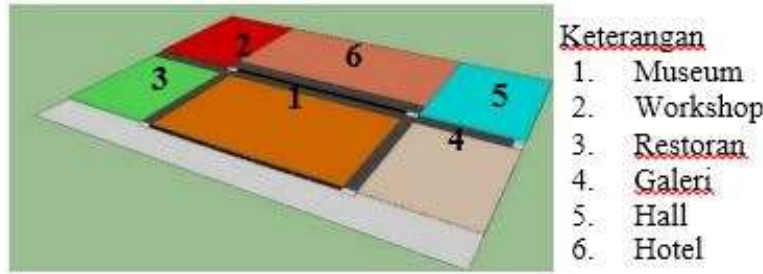

Gambar 3. Pemintakatan Sentra Batik

\subsection{Analisis Faktor Bangunan 3.3.1 Analisis Tampilan Bangunan}

Untuk tampilan bangunan (Surasetja, 2007) Sentra Batik Surakarta masih mengadopsi pemilihan warna dan material bangunanbangunan setempat (sesuai dengan penerapan teori Kearifan Lokal), dimana bangunan sekitar masih kental dengan Arsitektur Jawa. Hal tersebut ditunjukkan dengan penggunaan material batu alam, ukiran-ukiran kayu serta atap berbentuk Joglo.

Bentuk tampilan bangunan tidak hanya mengadopsi dari bentuk bangunan sekitar, tetapi mengambil bentuk dari motif batik. Motif batik yang diaplikasikan ke bangunan yaitu batik truntum dan batik parang.

Pemilihan bentuk motif batik didasarkan dari filosofi motif batik itu sendiri (Wulandari, 2011).

Motif batik truntum memiliki makna cinta yang tumbuh kembali, sebagai simbol cinta yang tulus tanpa syarat, abadi dan semakin lama terasa semakin berkembang (tumaruntum). Pengaplikasian ke dalam kawasan dengan maksud agar batik tumbuh kembali dengan cinta yang tulus dan akan terus berkembang dan abadi.

Motif parang memiliki makna perjuangan untuk mencari kebahagiaan lahir dan batin. Pengaplikasian ke dalam bangunan sebagai elemen dinding yang diaplikasikan ke bangunan galeri, dapat dilihat pada Gambar 4.

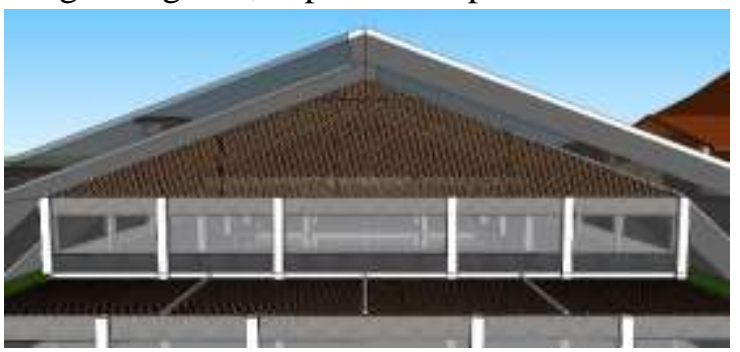

Gambar 4. Aplikasi Motif Batik Parang ke Galeri
Motif batik kawung memiliki makna keinginan dan usaha yang keras akan selalu membuahkan hasil. Pengaplikasian ke dalam bangunan sebagai elemen dinding yang diaplikasikan ke bangunan hall, dapat dilihat pada Gambar 5.

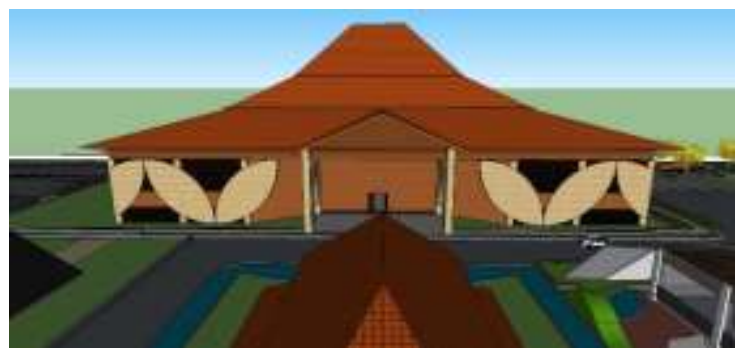

Gambar 5. Aplikasi Motif Batik Kawung ke Hall

\subsubsection{Analisis Gubahan Massa}

Bentuk tampilan bangunan Sentra Batik sesuai dengan konsep Kearifan Lokal, dapat dilihat pada Gambar 6 .

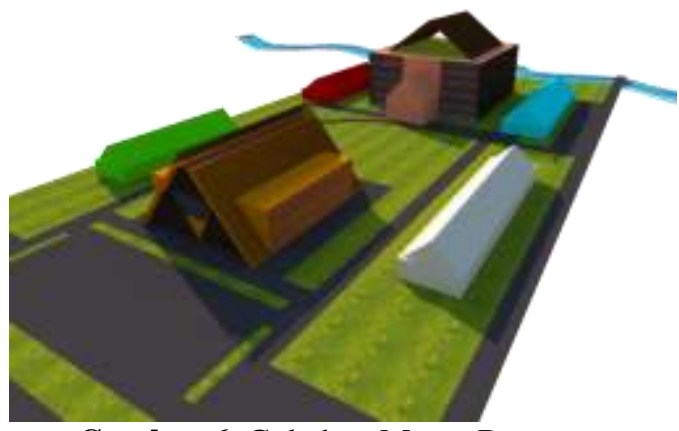

Gambar 6. Gubahan Massa Bangunan

Dari gubahan massa bangunan terlihat memiliki masa yang majemuk. Beberapa massa dalam satu kawasan. Ada dua fungsi massa yaitu kegiatan utama dan kegiatan pendukung.

\section{KESIMPULAN (KONSEP DESAIN)}

Konsep rancangan Sentra Batik mengacu pada budaya lokal sekitar yang fungsional dipadukan oleh budaya batik. Kehidupan yang semakin modern membuat busana akan batik mulai punah. Dengan membuat wadah untuk pengusaha batik dan membuat tempat wisata batik akan menggugah minat masyarakat akan hal batik.

$\begin{array}{ll}\text { Nama } & : \text { Sentra Batik } \\ \text { Lokasi } & : \text { Karangasem, Surakarta. } \\ \text { Luas Lahan } & : 50.000 \mathrm{~m}^{2} \\ \text { Kegiatan } & : \quad \text { Belanja, Pameran, } \\ \text { Pengetahuan } & \text { Sejarah dan Pelatihan, Resto dan } \\ \text { Penginapan. } & \end{array}$


Untuk kawasan Sentra Batik memiliki beberapa area, yaitu area parkir, area penerima, area taman, area galeri, area hall, area resto, area museum dan workshop dan area hotel.

Budaya batik diterapkan ke dalam bangunan dijadikan bentuk dasar bangunan dan ornamen pada dinding bangunan. Dari hasil analisa yang telah dilakukan, maka diperoleh hasil berupa rancangan Sentra Batik di Surakarta, dapat dilihat pada Gambar 7.

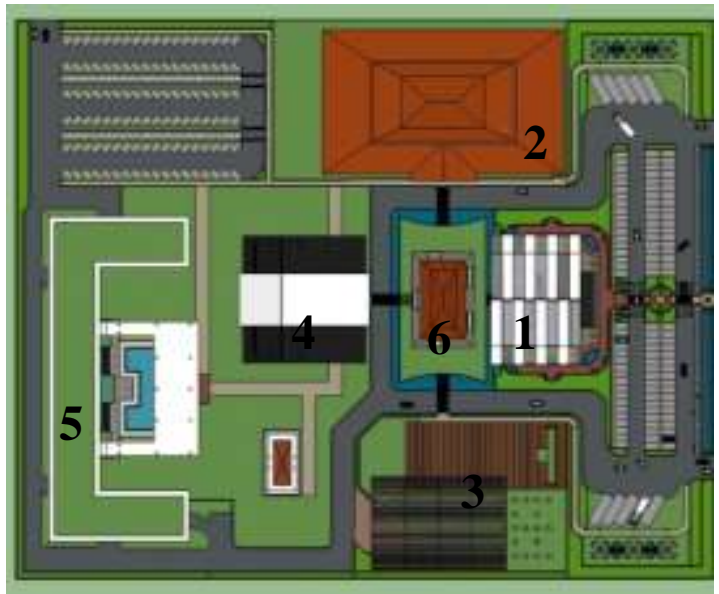

Gambar 7. Rencana Tapak Sentra Batik
Keterangan
1. Galeri
2. Multi Purpose Hall
3. Restoran
4. Museum dan Workshop
5. Hotel
6. Ruang Penerima

Hasil desain Sentra batik pada Gambar 8.

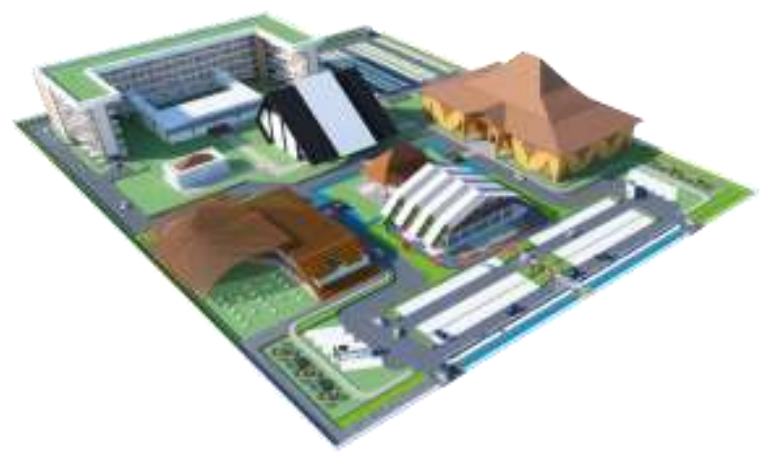

Gambar 8. Hasil Desain Sentra Batik

Konsep Kearifan Lokal (Local Wisdom) yang diterapkan ke kawasan Sentra Batik, yaitu bentuk bangunan lokal atap Joglo yang diterapkan ke bangunan hall, dapat dilihat pada Gambar 9.

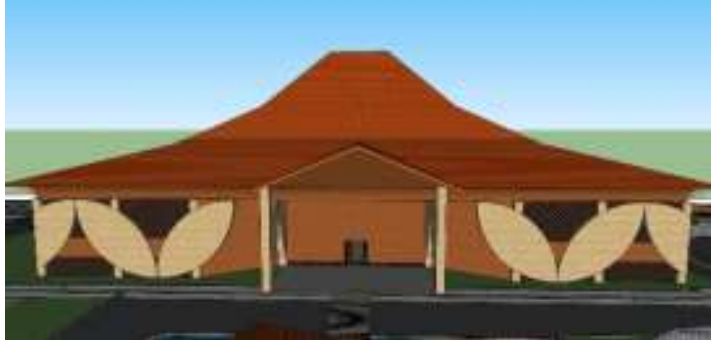

Gambar 9. Atap Joglo Pada Hall

Bentuk atap limasan yang diterapkan ke bangunan galeri dan museum dengan ada sedikit perubahan pada atap limasan, dapat dilihat pada Gambar 10.

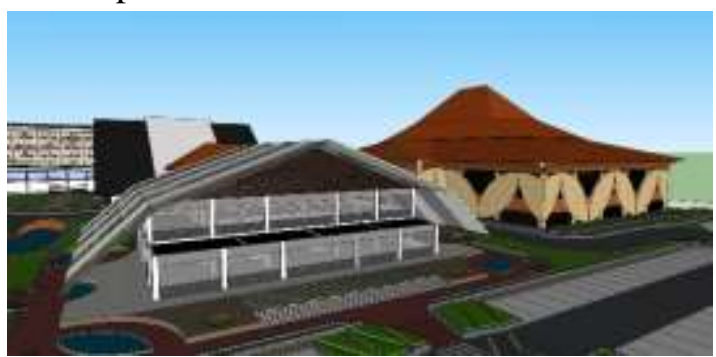

Gambar 10. Atap Limasan Pada Galeri

Kemudian elemen-elemen bangunan yang diambil dari motif batik parang dan kawung yang diterapkan ke bangunan hall sebagai dinding dan secondary skin, dapat dilihat pada Gambar 11.

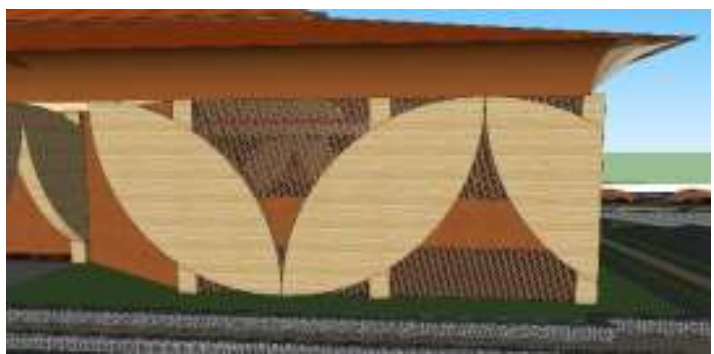

Gambar 11. Motif Parang dan Kawung Pada Hall

Motif parang sebagai bukaan pada bangunan galeri, dapat dilihat pada Gambar 12 .

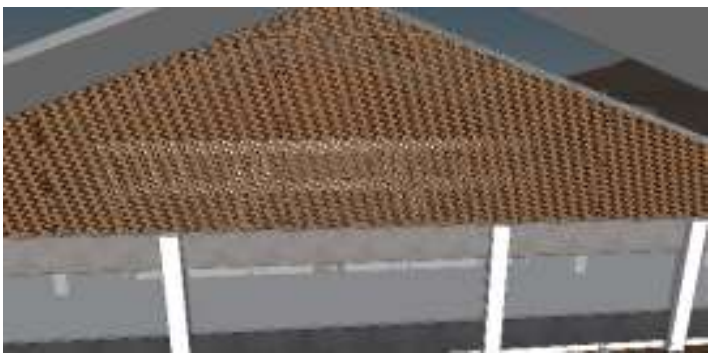

Gambar 12. Motif Parang Pada Galeri 


\section{REFRENSI}

Ayat, Rohaedi, 1986, Kepribadian Budaya Bangsa (Local Genius), Jakarta : Pustaka Jaya.

Wulandari, Ari, 2011, Batik Nusantara (makna filosofis, cara pembuatan \& industri batik), Jakarta : Gramedia.

Surasetja , Drs. R. Irawan, MT. (2007), Fungsi, Ruang, Bentuk Dan Ekspresi Dalam Arsitektur. 